
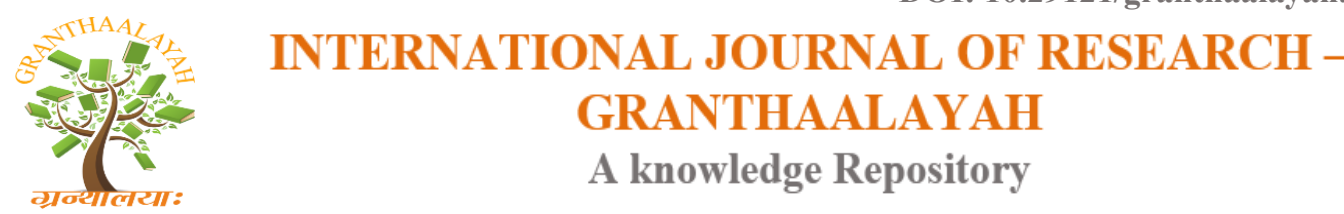

Management

\title{
A STUDY ON BRAND PREFERNCE OF CONSUMERS IN PURCHASING HAIR DYE IN TIRUNELVELI CITY
}

\author{
Dr. A. Hamil ${ }^{* 1}$, Muniswari.M ${ }^{2}$ \\ ${ }^{* 1}$ Associate Professor of Commerce and Dean of Arts, Sadakathullah Appa College, \\ Tirunelveli, INDIA \\ ${ }^{2}$ M.Phil. Scholar, Department of Commerce, Sadakathulla Appa College, Tirunelveli, INDIA
}

\begin{abstract}
Hair dye use is very common among both Men \& Women. Hair dye users are increasing day by day coloring of hair is performed not only by professionals but also a popular cosmetic product. Hair dye is used mostly to change gray hair, since gray hair is a sign of an advanced age. Most of them are using hair dye in our home. Earlier natural hair dyes were used but now due to advancement in cosmetic industry, different types have been developed. There has been concern about hair dye since scientist is trying to find out if there is a link between hair color and cancer.
\end{abstract}

Keywords:

Hair dye relationship between age group, education, allergy.

Cite This Article: Dr. A. Hamil, and Muniswari.M, "A STUDY ON BRAND PREFERNCE OF CONSUMERS IN PURCHASING HAIR DYE IN TIRUNELVELI CITY” International Journal of Research - Granthaalayah, Vol. 4, No. 3: SE (2016): 57-62.

\section{INTRODUCTION}

\section{HISTORY OF HAIR DYE}

The dyeing of hair is an ancient art. In ancient times, the dyes were obtained from plants. Some of the most well-known are henna (lawsoniainermis), indigo, cassia obovata, senna, turmeric and amla. Others include katam black, walnut hulls, red ochre and leeks. In the 1661 book eighteen books of the secrets of art \& nature various methods of coloring hair black, gold, green, red, yellow, and white are explained. The development of synthetic dyes for hair is traced to the 1860s discovery of the reactivity of PPD with air. Hair dyeing is now a multibillion dollar industry that involves the use of both plant- derived and synthetic dyes.

\section{TYPES OF HAIR COLORING}

The four most common classifications 
- Permanent hair color

- Semi - permanent

- Temporary.

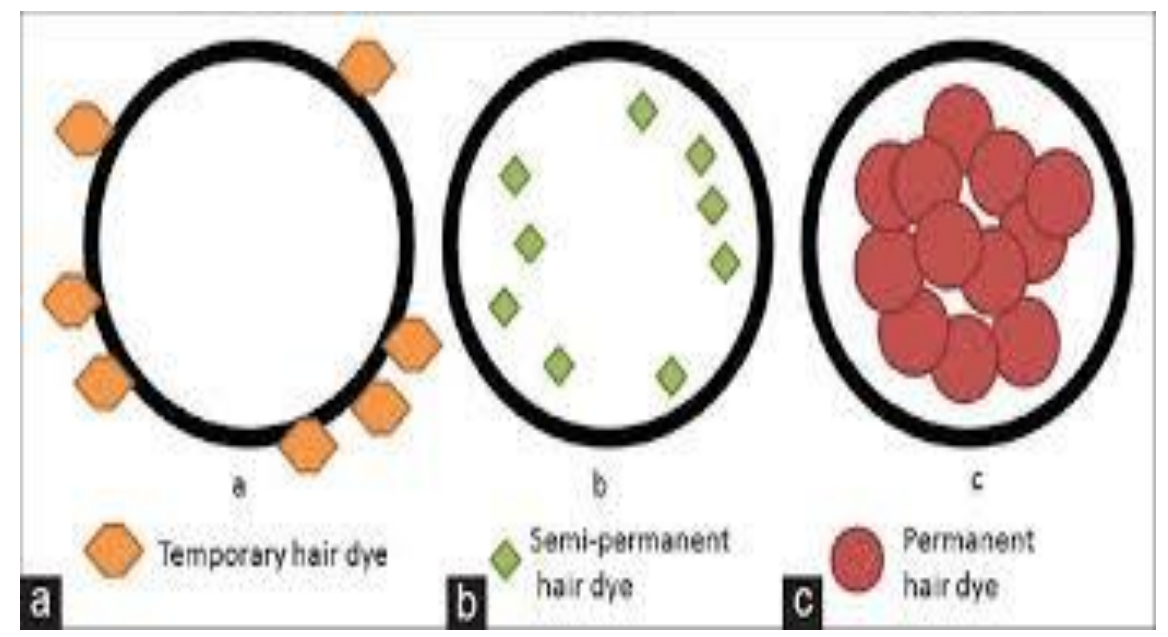

\section{ADVERSE EFFECTS OF HAIR COLORING}

Hair coloring involves the use of chemicals capable of removing, replacing and/or covering up pigments naturally found inside the hair shaft. Use of these chemicals can result in a range of adverse effects, including temporary skin irritation and allergy, hair breakage, skin discoloration and unexpected hair color results.

Side effects of various products result in loss of hair and in extreme cases balding. If consumed by the body by means of inhalation or digestion certain hair dye brands have shown evidence of causing constipation and other dangerous disruptions within human organs.

Additionally, there is ongoing discussion regarding more serious health consequences of hair color usage, including lead poisoning.

\section{STATEMENT OF PROBLEM}

Hair dye is becoming very popular among common people. Both men and women are interested in changing the color of their hair to various reasons. As such the marketers are offering different brands of hair dye to cater the needs of the consumers though several brands of hair dyes are available in the market, the satisfactory level of the consumers still remains a question mark. Hence the researcher felt it worth studying the health hazards of using hair dye and satisfaction level of consumers in using hair dye.

\section{OBJECTIVES OF THE STUDY}

- To know the awareness of ingredients in hair dye

- To study the health hazards of using hair dye

- To study the satisfaction level of the consumers regarding hair dye. 


\section{REVIEW OF LITERATURE}

Determining the extent of hair damage due to the time hair is submerged in hair dye. Breaks in the hair shaft increases although damage increase at a steady rate from $20 \mathrm{mins}$ to $30 \mathrm{mins}$, the rate of damage decreased after $80 \mathrm{mins}$.the decrease in hair demage is due to ammonia being used up as reagents. Victor H.Tran 2005.

Hair dye was started at an early age irrespective of their economic and education status volunteers dyed their hair which emphasizes the importance given to appearance. Majority used temporary dyes even though they perceived natural dyes were safe. Dharmistha Patel, Sarala Narayana and Bhuvana Krishnasamy 2013.

The purpose of dyeing and bleaching hair weakens its strength and to see if different hair structures that were uncolored differed in strength. Sandra Velasquez 2006.

A review of aspects of oxidative hair dye chemistry with special references to nitrosamine formation material 2013, 6: 517-34 Lewis D, Hawis J

\section{SAMPLING}

The researcher has selected 100 samples of hair dye users of Tirunelveli city. The samples are selected by adopting convenience sampling. Due care has been taken to include samples from different parts of Tirunelveli city.

\section{DATA ANALYSIS AND HYPOTHESIS TESTING}

The collected data have been tabulated and analyzed by using the statistical tools such as weighted ranking technique. To test the hypothesis defined, the statistical tool chi square test are used.

The following are the hypothesis to be tested:

- There is no significant relationship between age group and allergy in using hair dye

- There is no significant relationship between education and aware of ingredients in hair dye

\section{STATISTICAL TOOLS}

Statistical methods are the mechanical process specially designed to facilitate the condensation and analysis of the large body of quantitative data. The researchers has adopting weighted ranking, chi square method to analyse the data

\section{PERIOD OF STUDY}

A study on Brand Preference of consumers in purchasing hair dye covers the period of past three month November 2015 to January 2015. 


\section{LIMITATION OF THE STUDY}

- The study is restricted to 100 respondents only.

- The study is conducted only in tirunelveli city.

- The researcher has undertaken this study for the past three months only.

\section{CHI - SQUARE ANALYSIS}

\section{Hypothesis testing 1}

There is no significant relationship between age group and allergy in using hair dye

\begin{tabular}{|l|l|l|l|l|}
\hline Observed frequency & Expected frequency & O-E & {$[\mathbf{O}-\mathbf{E}]^{2}$} & $\frac{[\mathbf{O}-\mathbf{E}]^{2}}{\mathbf{E}}$ \\
\hline 10 & 9.89 & 0.11 & 0.0121 & 0.0013 \\
\hline 18 & 17.79 & 0.21 & 0.0441 & 0.0025 \\
\hline 25 & 21.16 & 3.84 & 14.7456 & 0.7696 \\
\hline 10 & 10.95 & 0.95 & 0.9025 & 0.0824 \\
\hline 5 & 8.21 & 3.21 & 10.3041 & 1.2550 \\
\hline 5 & 5.11 & 0.11 & 0.0121 & 0.0029 \\
\hline 8 & 8.21 & 0.21 & 0.0441 & 0.0053 \\
\hline 5 & 8.84 & 3.84 & 14.7456 & 1.6680 \\
\hline 6 & 5.05 & 0.95 & 0.9025 & 0.1787 \\
\hline 8 & 4.79 & 3.79 & 0.3041 & 2.7188 \\
\hline Total & & & & $\mathbf{6 . 6 8}$ \\
\hline
\end{tabular}

Degrees of freedom $=[\mathrm{r}-1][\mathrm{c}-1]$

Significant level at $5 \%$

$$
[2-1][5-1]=4
$$

Table value of $x^{2}$ for degrees of freedom 4 at $5 \%$ level of significance $=9.488$ $\mathrm{x}^{2}=6.68$ 
$6.68<9.488$

Since the table value is greater than calculated value. Then null hypothesis should be accepted.

\section{CONCLUSION}

There is no significant relationship between age group and allergy in using hair dye.

\section{Hypothesis testing 2}

There is no significant relationship between education and aware of ingredients in hair dye.

\begin{tabular}{|l|l|l|l|l|}
\hline Observed frequency & Expected frequency & O-E & {$[\mathbf{O}-\mathbf{E}]^{2}$} & \multicolumn{1}{|c|}{$\frac{\left[^{\mathbf{O}-\mathbf{E}}\right]^{2}}{}$} \\
\hline 5 & 10.68 & 5.68 & 32.2624 & 3.7169 \\
\hline 15 & 16.21 & 1.21 & 1.4641 & 0.1030 \\
\hline 27 & 24.68 & 2.32 & 5.3824 & 0.2273 \\
\hline 33 & 28.48 & 4.52 & 20.4304 & 0.7174 \\
\hline 8 & 2.32 & 5.68 & 32.2624 & 13.9062 \\
\hline 5 & 3.73 & 1.27 & 1.6129 & 0.4324 \\
\hline 4 & 6.32 & 2.32 & 5.3824 & 0.8516 \\
\hline 3 & 7.58 & 4.58 & 20.9664 & 2.7673 \\
\hline Total & & & & $\mathbf{2 2 . 7 2 2 1}$ \\
\hline
\end{tabular}

Degrees of freedom $=[\mathrm{r}-1][\mathrm{c}-1]$

Significant level at $5 \%$

$$
[2-1][4-1]=3
$$

Table value of $x^{2}$ for degrees of freedom 4 at $5 \%$ level of significance $=7.815$

$\mathrm{x}^{2}=22.72$

$7.815<22.72$

Since the calculated value is greater than table value. Then null hypothesis should be rejected. 


\section{CONCLUSION}

There is significant relationship between education and aware of ingredients in hair dye.

Satisfaction level of branded hair dye product

\begin{tabular}{|l|l|l|l|l|}
\hline S. no & Opinion & Weightage & No of respondents & Xw \\
\hline 1 & Highly satisfied & 1 & 45 & 45 \\
\hline 2 & Satisfied & 2 & 37 & 74 \\
\hline 3 & Neutural & 3 & 10 & 30 \\
\hline 4 & Dissatisfied & 4 & 5 & 20 \\
\hline 5 & Highly dissatisfied & 5 & 3 & 15 \\
\hline & & W.A & 100 & 184 \\
\hline
\end{tabular}

\section{FINDINGS}

- Most of the respondents under study are male.

- More number of respondents belongs to the age group of 35-45 years.

- Majority of the respondents have passed their post-graduation.

- Most of the respondents are married.

- Monthly income of most of the respondents are earning rupees 10000 -25000per month

- Most of the respondents prefer to buy Revlon brand.

- Most of the respondents are satisfied with the hair dye.

- There is no significant relationship between age group and allergy in using hair dye.

- There is significant relationship between education and aware of ingredients in hair dye

- There is significant relationship between education and aware of ingredients in hair dye.

- Regarding the various problems are faced by the respondents risk of cancer has placed the first rank.

\section{CONCLUSION}

In these studies says hair dye was started at a middle age irrespective of their economic and education status volunteers dyed their hair which emphasizes the importance given to appearance. Majority used permanent dyes even though they perceived natural dyes were safe. Hair dye marketers should focus more on including natural products in their product portfolio.

\section{REFERENCE}

[1] Gupta.S.P(2011) Statistical Methods, Sultan Chand and sons

[2] Pillai.R.S.N.,Bagavathi (2009), Modern Marketing, S.Chand \& company Ltd., New Delhi.

[3] www. Google.com

[4] www. Scribed.com

[5] www.mbaparadise.com 